\title{
SOME CASES OF FAMILY DISSEMINATED SCLEROSIS.
}

BY ERNEST S. REYNOLDS, M.D. (LOND.), F.R.C.P.

Visiting Pinysician to the Manchester Workhouse Infirmary; Assistant Physician to the Manchester Royal Infirmary.

CAsEs of disseminated sclerosis occurring in families are so rare that the following are worth putting on record, and they also illustrate very well the aberrant types of disseminated sclerosis often so difficult to diagnose with certainty.

\section{The Family X.}

The first case to come under my notice was John X., the fourth child, whom I saw originally in May, 1898. He was then 30 years of age, and while in India, some months before, he had noticed that he became easily tired, that then his gait became very uncertain, and finally so altered that he was sent home. When I saw him he was very ataxic in the movements of his hands, arms and legs; his gait was so uncertain that he somewhat at first sight resembled a case of tabes dorsalis, but there was a little dragging of the feet (spastic gait) and it was found that his knee-jerks were much increased, and ankle clonus was present on both sides. It was almost impossible, owing to the ataxia, for him to write, and there was slurring of the speech, but no true "scanning." The patient was peculiarly emotional, and if he was moved suddenly to laughter his head dropped forward, his sense of equilibrium failed him, and he would have dropped to the ground if he had not been at once supported. There was no nystagmus, no paralysis of eye muscles, and no optic atrophy.

Since 1898 he has, with occasional remissions, much improved; there is now but slight incoördination in walking, 
but if anyone present makes a humorous remark his friends always at once rush to him to prevent his falling, as the incoördination comes on with laughing as before. $\mathrm{He}$ has lately developed a goître, but has no tachycardia and no fine tremors.

The second child, Mary X., aged now 37, came to see me in September, 1900, and was then, suffering principally from acid dyspepsia; but she also stated that she had had three attacks of "neuralgia," starting from the right shoulder and reaching round to the right breast. She had been suffering also for three weeks from some numbness of the outside of the left thigh, and for five days in the right thigh also. She said the numbness reached almost to the waist, but that it was not a total loss of sensation, and on testing it was very difficult to make out exactly where the numbness was, as her replies were so uncertain. Knowing, as I will relate later, how neurotic the family was, I thought it likely that most of her troubles were "functional," but in September, 1902, she again came to see me, saying that the numbness of her legs was better:, but that for ten days she had had numbness of the right hand, which she attributed to having carried a heavy basket a few days before. Again on examination it was impossible to say exactly where the numbness was, but I noticed a slight slurring and slowness of the speech. Three days later the paræsthesia and partial numbness had extended over the whole right side of the body, and she had become irritable in temper. In July, 1903, the last time I saw her, the peculiar sensory disturbances had reached to the head and were still on the right side of the body and right limbs; there was great uncertainty of movement with the right hand, the "excursions" in unnecessary directions being marked; she could only hold a pen with difficulty and her handwriting was very sprawling and infantile; there was slight atrophy of the thenar muscles of the right hand. No other symptoms or signs of any kind were present, and the eyes were normal in all respects. Since that date I hear she has been "better and worse," but she has developed nothing further.

The sixth child, Edward X., now aged 30, came to see me on January 24, 1902. For three years before this time he 
had much work and worry, and suffered from constipation, but he was fairly well until the hot weather in the summer of 1901, when on several occasions, while playing tennis or cricket, he suddenly lost control of the left leg, and fell down. At the end of November, 1901, he noticed slight numbness of the fingers of the left hand, especially in the thumb and index finger. A few days before his visit to me he noticed that the sight of the right eye was blurred, and I found he could not distinguish a face at the distance of four feet. He also told me that in 1895 he had double vision, which lasted for two months. There was no nystagmus; the right optic disc was very indistinct, probably from a descending neuritis; his speech was very slow and slurring, but not scanning. He has never had syphilis. I have not had another opportunity of examining this patient, but I am informed by his doctor that he has improved very much, except that the speech is still slow.

The rest of the family history is somewhat remarkable.

The father, aged 66 , was strong and healthy up to about eighteen months ago, when, after a monetary loss, he became somewhat depressed, and is now suffering from melancholia, with delusions of poverty and unworthiness, and is, probably, suicidal. A first cousin (male) of the father died some years ago from advanced disseminated sclerosis, and a cousin of this man (a girl) came to see we a few weeks ago suffering from very marked exophthalmic goître.

The sister of the mother of the $\mathrm{X}$. family came to see me in 1900, when she was 52 years of age. She was suffering from insomnia and melancholia, with ideas of unworthiness and an inability " to find comfort in her religion."

The other children of the family $\mathrm{X}$. have been three in number. The eldest was a female, who died in an asylum while suffering from melancholia. The second is Mary, mentioned above; the third is a female, who suffers periodically from severe sciatica; the fourth is John, mentioned above ; the fifth is a male, now living abroad, and said to be well; the sixth is Edward, mentioned above.

Although on paper it may seem that the signs and symptoms manifested by the three children suffering from 
disseminated sclerosis are slight, yet to the patients themselves they are very disabling, and especially so in the case of John. They are in a good social position, and their many engagements are much interfered with by their disease. It may possibly be thought from my description that a diagnosis of disseminated sclerosis is not justified in all the cases; but the symptoms are, on personal examination, much more pronounced than can be easily described. It is so difficult to exactly pen what the ear detects in the altered speech and what the eye sees in the slightly unsteady movements when definite actions are performed. At least two of the cases have been seen also by eminent London neurologists, who have at once confirmed the diagnoses.

\section{The Family $Y$.}

Miss Jane Y., aged 25, was brought to see me by Dr. Sellers, of Rochdale, on April 12, 1904. About ten years ago she suffered from pains in the head and eyes. About five years ago she had double vision when looking to the right, but this only lasted a few months. Four years ago she conmenced to walk badly, was unsteady in her gait, and occasionally stumbled; rarely, her legs suddenly gave way, and she fell to the ground. She was seen about this time by a well-known and highly-experienced neurologist, who could find no real indications of organic disease, and thought it probable that the symptoms were functional. Since that time she has had remissions and relapses; for a time she had numbness of the left side of the body.

When I saw her the gait was very slightly spastic in character, and when turning round suddenly there was a little uncertainty of movement. There was no sign of actual paralysis, but some uncertainty in using the hands. The knee-jerks were increased, but there was no ankle clonus. She said she had occasional slight numbness of the right index finger, but no definite alteration of sensation could be found on examination. Sometimes the handwiting is bad, and her speech is very slightly slurring, thick, and nasal, and her father said that at times he could hardly understand 
what she said. There is no nystagmus, no paralysis of eye muscles, and the optic discs are normal.

The family $Y$. consists of three daughters-Mabel, aged 29 ; Cissy, aged 27; and Jane (mentioned above), aged 25. Cissy is in good health, but Mabel is suffering from advanced disseminated sclerosis, as will be seen from the following account, kindly supplied to me by Dr. Sellers. In the early part of the year 1900 she had been walking badly, and sometimes fell. In August, 1900, she had an attack of influenza, after which she suddenly "went stiff all over." In October, 1900 , she was seen by a physician, who diagnosed lateral sclerosis, and said she would only live six months. She became quite an invalid, and had to be carried downstairs. In April, 1901, she improved somewhat, was able to be dressed and sit out of doors, and in May was able even to walk upstairs. In November, 1901, she became worse, had to stay in bed, and could not move her left leg. Since that time she has gradually got worse, and now (March, 1904) she is scarcely able to walk even by holding on to a chair. Her right arm is tremulous, and she cannot hold anything with it; her speech is thick and scanning. There is no nystagmus.

The father tells me that Jane is "just like" Mabel was at the beginning of the latter's illness.

\section{COMmentary.}

Heredity.-As I have already stated, it is rare to find instances of disseminated sclerosis running in families. Sir Wm. Gowers says ("Diseases of Nervous System," vol. ii., p. 544) : "Direct heredity, or the affection of two brothers or sisters, has been noted in a few instances, but is quite exceptional; indirect inheritance is more common, shown by a family history of insanity, epilepsy, or of some form of chronic paralysis." Dr. Risien Russell, in his excellent account of the disease ("Allbutt's System of Medicine," vol. vii., p. 51), says: "It has only happened exceptionally that any direct hereditary connection has been traced, or that more than one member of the family has been affected;" and he 
mentions two observations by Leuch and Eichhorst in both of which a mother and child were affected. I am inclined to think, however, that the more we become familiar with the aberrant types of disseminated sclerosis, the more it may be found to occur in families; that is to say, where one member of a family has typical disseminated sclerosis, another member who has been diagnosed to be merely "neurotic" may really be found to be suffering from aberrant disseminated sclerosis. The family $\mathrm{X}$. also illustrates well the connection of the disease with mental diseases in the same family.

Type of disease.-It will be noticed that most of the cases reported are suffering from the irregular or aberrant type of disseminated sclerosis, a condition which ought to be better known and studied, for these cases are frequently diagnosed as hysteria, with lamentable results, especially for the diagnostician. It is unnecessary bere to give a lengthy account of aberrant disseminated sclerosis, as such an account is so easily accessible in Dr. Risien Russell's article referred to above; but it may not be out of place to epitomise the points illustrated by my cases, and which enabled me to make my diagnoses. These are: Irregular subjective patches of numbness, often varying, disappearing and reappearing; sudden falls from giving way of a leg; slight paralysis of hands, lasting for months or years; transitory paralyses of eye muscles; optic atrophy; subjective feelings of giddiness; alteration of handwriting; sudden dropping of articles held in the hand; ataxic movements of hands, and sometimes of feet; spastic condition of legs, with true ankle clonus, Babinski's toe extension reflex (if any reflex is obtained at all ${ }^{1}$ ); alteration of speech, even very slight (a sign which I consider of the utmost value). In the early stage the speech may not be "scanning," but may be a "slur" not unlike that found in early paralysis of the insane, or it may be a slight difficulty in forming certain words.

Prognosis.-Not only from observing for long periods many cases of aberrant disseminated sclerosis, but also from observations on the fully-developed disease (especially in the Man-

\footnotetext{
1 This reflex was not tested for in the $\mathrm{X}$. family. Jane $\mathrm{Y}$. did not respond to sole irritation.
} 
chester Workhouse Infirmary, where cases remain for many years), I am of opinion that the hopeless prognosis so often given in these cases is hardly justifiable. I do not mean that disseminated sclerosis recovers, but $I$ do think that it may last for many years, and that even when fully developed very great improvement may occur, so that a patient who has been bed-ridden may be able to walk about again and be comparatively comfortable. Moreover, the symptoms of the aberrant type may almost disappear (as in the case of John X. and Edward X.); at any rate they may last for many years without passing into the fully-developed disease. I think it is important that this should be more recognised, as one can truthfully instil hope and give encouragement to these sufferers.

Disseminated Sclerosis and Exophthalmic Goittre.-Last year a young lady was brought to see me who was suffering from disseminated sclerosis and from exophthalmic goitre, both fully developed. It will also be noticed that a cousin of the $X$. family suffers from exophthalmic goitre, and that John X. has developed a slight goitre. These cases may be, and probably are, the merest coincidences, but in such diseases as disseminated sclerosis and exophthalmic goitre, in which the etiology is so obscure, the coincidence seems to me to be worth bearing in mind. 